\title{
Transrectal ultrasound of the prostatic urethra related to urodynamically assessed urethral resistance A pilotstudy
}

Received: 2 September 1993/Accepted: 17 March 1994

\begin{abstract}
In this pilot study on 17 men who underwent urodynamic investigation for various dysuric complaints, real-time transrectal ultrasonography (TRUS) was performed. From the images anatomical parameters were identified that correlated with obstructive urodynamic findings and urethral resistance parameters based on pressure-flow analysis. This study gives support for further clinical investigations to determine the value of TRUS for male patients with dysuric disorders. It also illustrates the anatomical basis of prostatic obstruction as quantified by objective urodynamic parameters.
\end{abstract}

Key words Transrectal ultrasound $\cdot$ Urodynamics $\cdot$ Prostatism - Urethral resistance $\cdot$ Prostatic obstruction $\cdot$ Benign prostatic hyperplasia

Transrectal ultrasonography (TRUS) is useful in the imaging of the lower urinary pathways in both men and women $[1,10,11,14-16]$. During micturition in male patients the dynamic behaviour of bladder neck, prostate, prostatic urethra and pelvic musculature can be monitored. Obstructive dysuria in man is not always correlated with anatomical findings such as an enlarged prostate becoming apparent on digital rectal examination. In more than $50 \%$ of men over 50 years of age there is an impression of urethral occlusion, suggesting obstruction, on urethrocystoscopy, but less than $25 \%$ of these men require a prostatectomy to relieve obstruction during their lifetime [17]. Obstructive micturition can only be documented objectively by a full urodynamic evaluation in-

H. Jansen $(\bowtie)^{1} \cdot$ R. van Mastrigt $\cdot$ M. Kranse Department of Urology, Academic Hospital of Rotterdam and Erasmus University, Dr. Molewater plein 40, NL-3015 GD Rotterdam, The Netherlands

Present address: Department of Urology, Baronie Hospital, Langendijk 75, NL-4819 EV Breda, The Netherlands volving the measurement of detrusor pressure and flow rate $[9,12]$.

In this pilot study of 17 men TRUS measurements were compared with both conventional urodynamic parameters and computer-derived parameters quantifying urethral resistance and bladder contractility. Objective ultrasonic criteria were defined that correlate with both these.

\section{Materials and methods}

Of 21 men studied, 4 did not manage to void during the session with the transrectal probe in situ, and consequently no measurements of the urethra could be performed. In these 4 men no detrusor activity was seen; their free flow rate measurements showed an interrupted pattern in 3 cases while in 1 case the flow pattern was broad. This suggests that the 3 men with interrupted patterns had underactive detrusor muscles.

The remaining 17 patients (Table 1) were 43-83 years of age, with a mean age of 60 , and underwent voiding cystometry because of various dysuric complaints. Six patients $(1,2,10,12,13,15)$ suffered from prostatism-like complaints. In 3 patients $(4,14,16)$ dysuric complaints persisted after transurethral resection of the prostate (TURP). Prostatitis-like complaints were reported by 4 patients $(5,6$, $7,11)$ and 4 patients suffered from various neuropathic disorders: patients 3 and 9 from multiple sclerosis, patient 8 from panhypopituarism, and patient 17 from syringomyelia.

After an initial free flow rate measurement without catheters, patients underwent medium-fill cystometry with room temperature saline. Two 5-F urethral catheters were passed with lubrication, one to fill the bladder and the other to measure intravesical pressure. A water-filled 8 -F catheter was used to measure rectal pressure. Flow rate was measured using a DISA rotating disc flowmeter. From the chart recordings the parameters maximum flow rate, detrusor pressure during maximum flow, bladder capacity and bladder volume were derived. Residual urine was determined after voiding by emptying the bladder via the filling catheter. In 10 of these patients (Table 2) the voiding cystometry was stored using the computer program CLIM $[6,13]$. This program allows a PC to be connected to the urodynamic set-up to record and store detrusor pressure and flow rate signals during voiding. Using the program, the urethral resistance parameters URA [3] and OBI $[4,5]$ and the detrusor contractility parameter Wmax [2] were calculated from the stored signals. The parameter URA is derived from a statistical approximation of a quadratic pressure-flow relation fitted through the point of maximum flow rate and associated detrusor pressure. OBI is a 
Table 1 Conventional urodynamic parameters and transrectal ultrasound (TRUS) measurements of the prostatic urethra in 17 patients

\begin{tabular}{|c|c|c|c|c|c|c|c|c|c|}
\hline $\begin{array}{l}\text { Patient } \\
\text { no. }\end{array}$ & Age & $\begin{array}{l}\text { Flow } \\
(\mathrm{Q} \max \\
\mathrm{in} \mathrm{ml} / \mathrm{s})\end{array}$ & $\begin{array}{l}\text { Voided } \\
\text { volume (ml) }\end{array}$ & $\begin{array}{l}\text { Residual } \\
\text { volume (ml) }\end{array}$ & $\begin{array}{l}\text { Detrusor } \\
\text { pressure } \\
\left(\mathrm{cm} \mathrm{H}_{2} \mathrm{O}\right. \\
\text { at } \mathrm{Q} \text { max })\end{array}$ & $\begin{array}{l}\text { Diameter } \\
\text { of bladder } \\
\text { neck }(\mathrm{mm})\end{array}$ & $\begin{array}{l}\text { Diameter of } \\
\text { midurethra } \\
\text { (mm) }\end{array}$ & $\begin{array}{l}\text { Diameter } \\
\text { of apical } \\
\text { urethra } \\
(\mathrm{mm})\end{array}$ & $\begin{array}{l}\text { Total length } \\
\text { of prostatic } \\
\text { urethra ( } \mathrm{mm} \text { ) }\end{array}$ \\
\hline 1 & 59 & 3 & 250 & 30 & 65 & 1 & 2 & 0.5 & 45 \\
\hline 2 & 67 & 3 & 120 & 125 & 80 & 2 & 1.5 & 0.5 & 26 \\
\hline 3 & 43 & 6 & 80 & 250 & 37 & 4 & 3.5 & 1 & 16 \\
\hline 4 & 56 & 24 & 150 & 0 & 15 & 8 & 4 & 1 & 16 \\
\hline 5 & 56 & 12 & 320 & 50 & 30 & 1 & 1 & 1 & 25 \\
\hline 6 & 80 & 10 & 130 & 50 & 55 & 4 & 7 & 3.5 & 19 \\
\hline 7 & 53 & 18 & 320 & 0 & 40 & 7 & 4 & 3 & 18 \\
\hline 8 & 54 & 19 & 200 & 0 & 52 & 2.5 & 2.5 & 1.5 & 21 \\
\hline 9 & 37 & 14 & 270 & 170 & 40 & 3 & 5.5 & 2.5 & 17 \\
\hline 10 & 56 & 7 & 580 & 0 & 40 & 1.5 & 2.5 & 1.5 & 18 \\
\hline 11 & 42 & 14 & 280 & 0 & 50 & 1.5 & 4 & 2.5 & 18 \\
\hline 12 & 76 & 8 & 270 & 70 & 50 & 2.5 & 6.4 & 2.5 & 18 \\
\hline 13 & 53 & 7 & 180 & 75 & 95 & 1 & 1 & 0.5 & 21 \\
\hline 14 & 83 & 3 & 70 & 105 & 43 & 2.5 & 1 & 1 & 18 \\
\hline 15 & 67 & 3 & 90 & 50 & 33 & 1.5 & 4 & 1 & 14 \\
\hline 16 & 68 & 5 & 130 & 0 & 35 & 7 & 4.5 & 1 & 19 \\
\hline 17 & 51 & 11 & 150 & 30 & 20 & 2.4 & 1.5 & 0.5 & 18 \\
\hline
\end{tabular}

Table 2 TRUS measurements, resistance parameters URA and OBI and contractility parameter Wmax in 10 patients

\begin{tabular}{|c|c|c|c|c|c|c|c|}
\hline $\begin{array}{l}\text { Patient } \\
\text { no. }\end{array}$ & $\begin{array}{l}\text { Diameter } \\
\text { of bladder } \\
\text { neck }(\mathrm{mm})\end{array}$ & $\begin{array}{l}\text { Diameter } \\
\text { of midurethra } \\
(\mathrm{mm})\end{array}$ & $\begin{array}{l}\text { Diameter } \\
\text { of apical } \\
\text { urethra }(\mathrm{mm})\end{array}$ & $\begin{array}{l}\text { Total length } \\
\text { of prostatic } \\
\text { urethra }(\mathrm{mm})\end{array}$ & $\begin{array}{l}W \max \\
\left(W / m^{2}\right)\end{array}$ & $\begin{array}{l}\text { URA } \\
\left(\mathrm{cmH}_{2} \mathrm{O}\right)\end{array}$ & OBI \\
\hline 2 & 2 & 1.5 & 0.5 & 26 & 9.7 & 65 & 87 \\
\hline 3 & 4 & 3.5 & 1 & 16 & 5.1 & 24 & 33 \\
\hline 4 & 8 & 4 & 1 & 16 & 3.0 & 12 & 13 \\
\hline 6 & 4 & 7 & 3.5 & 19 & 4.3 & 19 & 20 \\
\hline 8 & 2.5 & 2.5 & 1.5 & 21 & 8.4 & 24 & 40 \\
\hline 11 & 1.5 & 4 & 2.5 & 18 & 8.1 & 26 & 40 \\
\hline 13 & 1 & 1 & 0.5 & 21 & 16.5 & 91 & 107 \\
\hline 14 & 2.5 & 1 & 1 & 18 & 5.4 & 33 & 44 \\
\hline 15 & 1.5 & 4 & 1 & 14 & 9.8 & 61 & 71 \\
\hline 16 & 7 & 4.5 & 1 & 19 & 6.2 & 40 & 39 \\
\hline
\end{tabular}

Fig. 1 Ultrasound image of the prostatic urethra of a 35 -yearold man with no symptoms. These images were used to measure the diameter of the urethra at the apex (l), midurethra (2) and bladder neck (3) at maximum flowrate

Fig. 2 Ultrasound image of a 72-year-old man with obstructive voiding. Measurements were taken at apex (l), midurethra (2) and bladder neck (3)
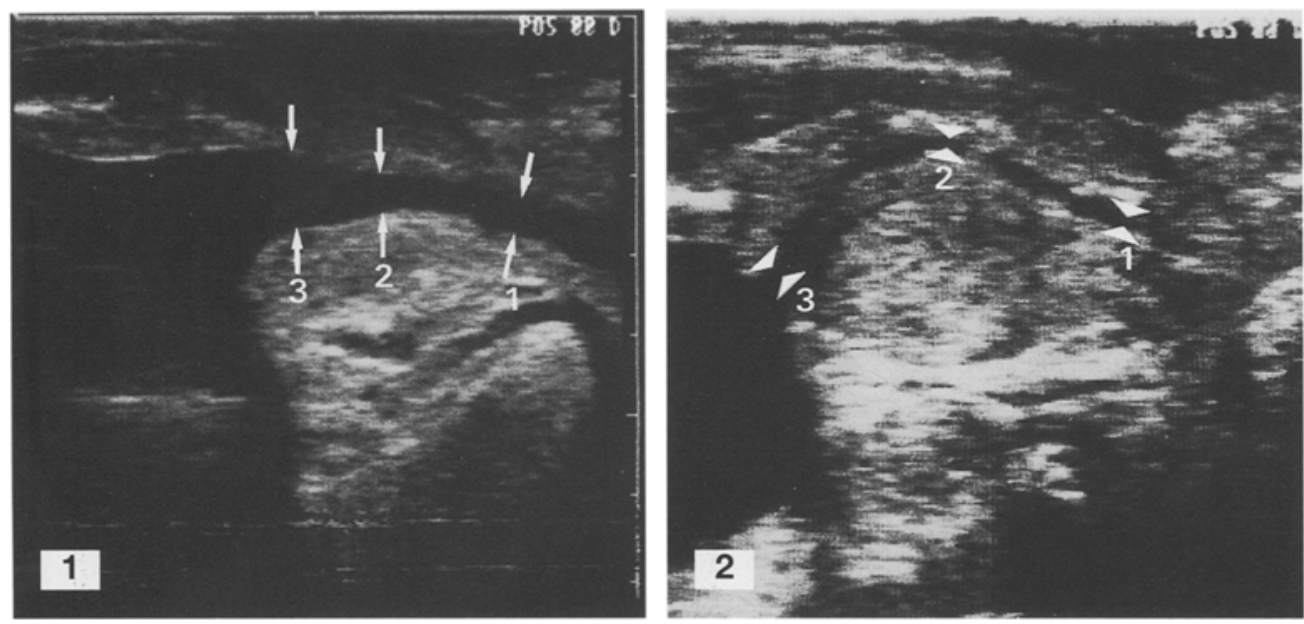

linear combination of the average height and average slope of the pressure-flow plot derived using Fisher's linear discriminant method. Both parameters are described in more detail elsewhere [8]. The contractility parameter, Wmax, is the maximum of an approximation of the power developed by the detrusor per surface area during voiding [12].
At the same time as the voiding study, TRUS was performed for visualization of bladder neck, prostate, prostatic urethra and pelvic musculature. A Toshiba $5 \mathrm{mHz}$ IVE-506S linear array probe was used for the examination, with patients in the sitting position on a chair. The examination session was recorded on videotape. The images recorded were used to measure the length of the prostatic 
Table 3 Correlation of conventional urodynamic parameters with diameter and length of the urethra. Urethral diameter was measured proximally, at the mid-urethra and apically. Diameters and length were determined by means of TRUS. Numbers shown are Spearman's rank correlation coefficients (and significances in parentheses) for 17 patients

$\begin{array}{llllll}\text { Urodynamic parameters } & \begin{array}{l}\text { Bladder } \\ \text { capacity }\end{array} & \begin{array}{l}\text { Maximum } \\ \text { flow rate }\end{array} & \begin{array}{l}\text { Detrusor } \\ \text { pressure at } \\ \text { max. flow }\end{array} & \begin{array}{l}\text { Bladder } \\ \text { volume }\end{array} & \begin{array}{l}\text { Residual } \\ \text { urine }\end{array}\end{array}$

Sonographic parameters

\begin{tabular}{|c|c|c|c|c|c|}
\hline Proximal diameter & $\begin{array}{c}0.30 \\
(0.12)\end{array}$ & $\begin{array}{l}-0.47 \\
(0.03)\end{array}$ & $\begin{array}{l}-0.19 \\
(0.24)\end{array}$ & $\begin{array}{l}-0.24 \\
(0.17)\end{array}$ & $\begin{array}{c}0.03 \\
(0.46)\end{array}$ \\
\hline Mid-urethral diameter & $\begin{array}{r}0.23 \\
(0.19\end{array}$ & $\begin{array}{l}0.0025 \\
(0.50)\end{array}$ & $\begin{array}{c}0.024 \\
(0.46)\end{array}$ & $\begin{array}{l}-0.26 \\
(0.15)\end{array}$ & $\begin{array}{c}0.03 \\
(0.45)\end{array}$ \\
\hline Apical diameter & $\begin{array}{c}0.54 \\
(0.012)\end{array}$ & $\begin{array}{l}-0.047 \\
(0.43)\end{array}$ & $\begin{array}{c}0.40 \\
(0.06)\end{array}$ & $\begin{array}{l}-0.12 \\
(0.32)\end{array}$ & $\begin{array}{c}0.38 \\
(0.06)\end{array}$ \\
\hline Urethral length & $\begin{array}{l}-0.23 \\
(0.19)\end{array}$ & $\begin{array}{c}0.64 \\
(0.003)\end{array}$ & $\begin{array}{c}0.13 \\
(0.31)\end{array}$ & $\begin{array}{l}-0.19 \\
(0.24)\end{array}$ & $\begin{array}{c}-0.22 \\
(0.20)\end{array}$ \\
\hline
\end{tabular}

Table 4 Correlation between objective parameters of urethral resistance (OBI, URA) and detrusor contractility (Wmax) determined using the computer program CLIM and diameter and length of the urethra. Urethral diameter was measured proximally, at the midurethra and apically. Diameters and length were determined by TRUS. Numbers shown are Spearman's rank correlation coefficients (and significances in parentheses) for 10 patients

$$
\text { CLIM parameters OBI URA }{ }^{\mathrm{w}} \max
$$

Sonographic parameters

\begin{tabular}{llll}
\hline Proximal diameter & -0.88 & -0.71 & -0.51 \\
& $(0.001)$ & $(0.011)$ & $(0.065)$ \\
Mid-urethral diameter & -0.66 & -0.48 & -0.45 \\
& $(0.018)$ & $(0.079)$ & $(0.096)$ \\
Apical diameter & -0.58 & -0.70 & -0.48 \\
& $(0.038)$ & $(0.013)$ & $(0.080)$ \\
Urethral length & 0.37 & 0.36 & 0.41 \\
& $(0.14)$ & $(0.15)$ & $(0.12)$ \\
\hline
\end{tabular}

urethra and the diameter of the proximal prostatic urethra (bladder neck), the mid-urethra and the apical urethra as sonographic parameters (Tables 1, 2, Fig. 1). These measurements were taken at the moment of maximum flow. The urodynamic and sonographic parameters were compared by calculating Spearman's rank correlation coefficient.

\section{Results}

In all 17 patients good visualization was attained. The musculature was inspected during both bladder filling and voiding. Tables 1 and 2 describe the parameters recorded in the patients who underwent urodynamic investigation and TRUS simultaneously.

Table 3 shows the correlation between the conventional urodynamic parameters and the sonographic parameters. There is a significant correlation between the width of the apical urethra and the maximum flow rate and between the length of the urethra and the diameter of the bladder neck and the detrusor pressure during maximum flow. The diameter of the middle section of the urethra did not correlate with any conventional urodynamic parameter. In 10 patients the voiding cystometry was stored and processed using the computer program CLIM. Table 4 shows the correlations between the resulting parameters and the sonographic parameters. There was a significant negative correlation of the urethral resistance parameter URA with the diameter of the proximal urethra and the apical urethra and a significant negative correlation of the urethral resistance parameter OBI with all three diameters measured. There were no significant correlations of the detrusor contractility parameter Wmax with the sonographic parameters.

\section{Discussion}

In this study, TRUS recordings were made of the prostate and the prostatic urethra during voiding in patients with dysuric complaints. Patients who strained during voiding all showed a clear collapse of the pre-prostatic blood vessels (Santorini plexus), and often a downward rotatory movement of the prostate could be seen, during which the apex was relatively immobile. In patients who had previously undergone TURP, resection seemed on TRUS to have been imcomplete until they started to void, when definite opening of the bladder neck and mid-urethra could be seen and only a small rim of prostatic tissue remained dorsally and ventrally. Apical remnants in one case showed a persistent obstruction that was urodynamically confirmed (Fig. 2). Patients with hyperplastic ventral lobes were seen during micturition to have a long prostatic urethra, because of the curvature of the urethra.

In 1 patient the bladder neck closed at the same time as the external sphincter at the end of micturition. At that moment a bolus of fluid was enclosed in the prostatic urethra, which suggests a cause of dribbling (Fig. 3).

The TRUS images allowed accurate determination of the diameter of the urethra at a number of locations and of the length of the urethra. In the limited material of this pilot study we found significant correlations between the 


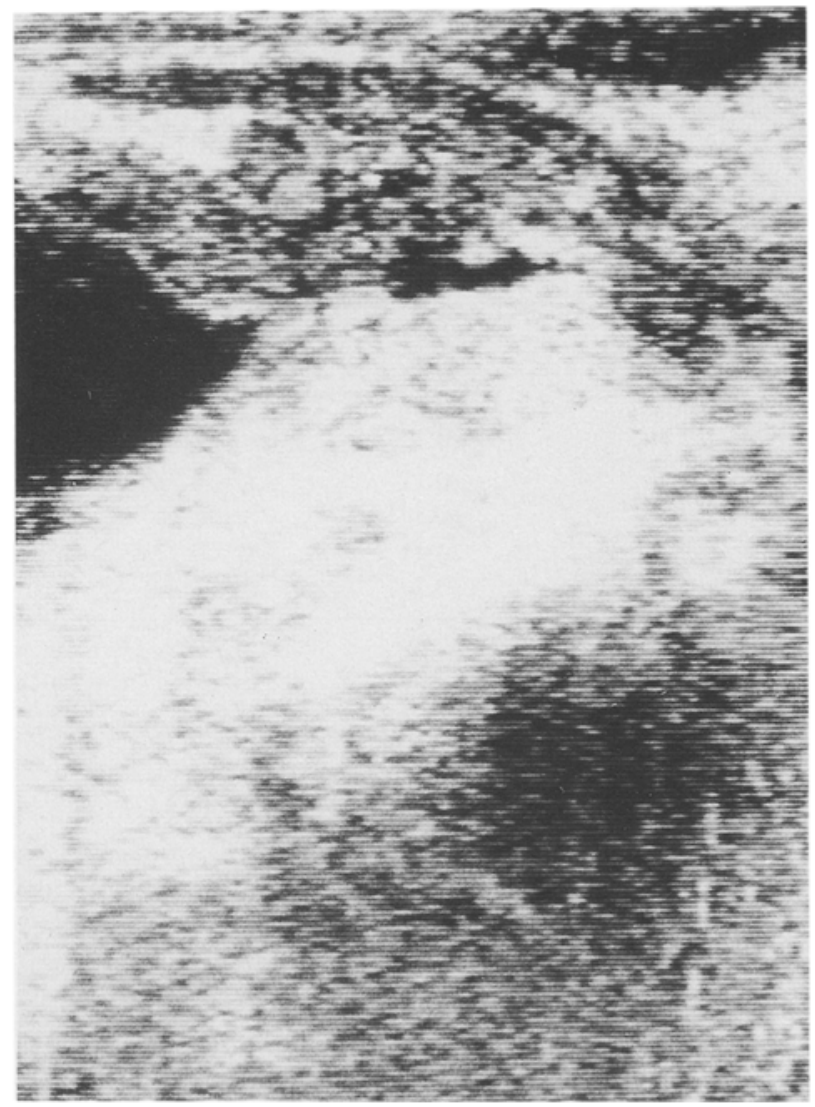

Fig. 3 Ultrasound image of the prostatic urethra of a man who had a bolus of urine enclosed in his prostatic urethra, illustrating a possible cause of dribbling following micturition

diameters of the urethra determined by TRUS and the urethral resistance as quantified by the parameters URA and OBI. The strongest correlations were found in the bladder neck region. Increased urethral resistance caused a decreased maximum flow rate. There was also a significant negative correlation between the diameter of the apical urethra and maximum flow rate.

Although this pilot study included only a limited number of patients, it can be concluded that there are measurable anatomical parameters of urethra and prostate that correlate with obstructive urodynamic findings. Transrectal manipulation is bound to interfere with normal micturition, and it is not therefore our intention to present this modality as a routine investigation in patients with dysuric problems. Nevertheless we think that TRUS is a modality that could be used for further fundamental investigation in poorly understood micturition disturbances such as outlet obstruction, dysuria and dribbling.

\section{References}

1. Fellows GJ, Cannell LB, Ravichandran G (1987) Transrectal ultrasonography compared with voiding cystourethrography after spinal cord injury. Br J Urol 59:218

2. Griffiths DJ, Constantinou CE, Mastrigt R van (1986) Urinary bladder function and its control in normal females. Am J Physiol 251-252: R 225-R 230

3. Griffiths DJ, Mastrigt R van, Bosch R (1989) Quantification of urethral resistance and bladder function during voiding, with special reference to the effects of prostate size reduction on urethral obstruction due to BPH. Neurourol Urodyn 8-1:17

4. Kranse M, Mastrigt R van (1991) Fitting orthogonal polynomals to the lowest part of a pressure flow plot. Neurourol Urodyn $10: 290$

5. Kranse M, Mastigt R van, Rollema HJ (1992) Resolution and specificity of parameters characterizing bladder outlet obstruction. Neurol Urodyn 11:394

6. Mastrigt $R$ van (1984) A computer program for on-line measurement, storage, analysis and retrieval of urodynamic data. Comp Prog Biomed 18:109

7. Mastrigt $R$ van (1990) Application of animal and physical models to human cystometry. In: Drife JO, Hilton P, Stanton SL. (eds) Micturition. Springer, London Berlin New York

8. Mastrigt $R$ van, Kranse M (1994) Automated evaluation of urethral obstruction. Urology 42:216

9. Mastrigt R van, Rollema HJ (1992) Prognostic value of bladder contractility in prostatectomy. J Urol 148:1856

10. Nishizawa O, Moriya I, Sato S, Harada T, Tsichida S (1982) A new video urodynamics: combined ultrasonotomographic and urodynamic monitoring. Neurourol Urodyn 1:295

11. Perkash I, Friedland GW (1986) Transrectal ultrasonography of the lower urinary tract: evaluation of bladder neck problems. Neurourol Urodyn 5:299

12. Rollema HJ, Mastrigt R van (1988) Accuracy of uroflowmetry in the differential diagnosis of infravesical obstruction and impaired detrusor contractility. Neurourol Urodyn $3: 228$

13. Rollema HJ, Mastrigt $R$ van (1992) Improved indication and follow up in transurethral resection of the prostate using the computer program CLIM: a prospective study. J Urol 148:111

14. Shabsigh R, Fishman IJ, Krebs M (1987) The use of transrectal longitudinal ultrasonography in urodynamics. J Urol 138:1416

15. Shapeero LG, Friedland GW, Perkash I (1983) Transrectal sonographic voiding cystourethrography: studies in neuromuscular bladder dysfunction. A J R 141

16. Vierhout ME, Jansen $H$ (1991) Supine and sitting rectal ultrasound of the bladderneck during relaxation, straining and squeezing. Int Urogynecol J 2:141

17. Walsh PC (1986) Benign prostatic hyperplasia. In: Walsh PC, Gittes RE, Perlmutter AD, Stamey TA (eds) Campbell's urology, vol 2 , chap 27. Saunders, Philadelphia 